\title{
A contemporary comparison of the effect of shunt type in hypoplastic left heart syndrome on the hemodynamics and outcome at stage 2 reconstruction
}

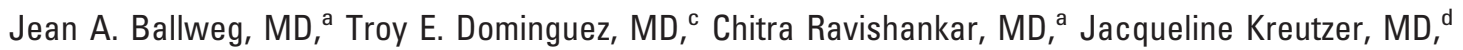
Bradley S. Marino, MD, ${ }^{\text {a,c }}$ Geoffrey L. Bird, MD, ${ }^{\text {a,c }}$ Peter J. Gruber, MD, PhD, Gil Wernovsky, MD, ${ }^{\text {a }}$ J. William Gaynor, MD, ${ }^{b}$ Susan C. Nicolson, MD, ${ }^{c}$ Thomas L. Spray, MD, ${ }^{b}$ and Sarah Tabbutt, MD, PhD ${ }^{a, c}$

Earn CME credits at http://cme.ctsnetjournals.org
From the Department of Pediatrics, Divi-

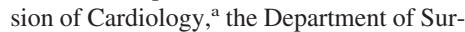
gery, Division of Cardiothoracic Surgery, ${ }^{b}$ and the Department of Anesthesiology and Critical Care Medicine, ${ }^{\mathrm{c}}$ Children's Hospital of Philadelphia and University of Pennsylvania School of Medicine, Philadelphia, $\mathrm{Pa}$; and the Department of Pediatrics, Division of Cardiology, ${ }^{\mathrm{d}}$ Children's Hospital of Pittsburgh and University of Pittsburgh School of Medicine, Pittsburgh, Pa.

Received for publication Feb 1, 2007; accepted for publication Feb 21, 2007.

Address for reprints: Jean Ballweg, MD, Cardiac Intensive Care Unit, The Children's Hospital of Philadelphia, 34th St and Civic Center Blvd, Philadelphia, PA 19119 (E-mail: ballweg@email.chop.edu).

J Thorac Cardiovasc Surg 2007;134:297-303 $0022-5223 / \$ 32.00$

Copyright $(92007$ by The American Association for Thoracic Surgery

doi:10.1016/j.jtcvs.2007.02.046
Objective: We compare the hemodynamics and perioperative course of shunt type in hypoplastic left heart syndrome at the time of stage 2 reconstruction and longer-term survival.

Methods: We retrospectively reviewed the echocardiograms, catheterizations, and hospital records of all patients who had a stage 1 reconstruction between January 2002 and May 2005 and performed a cross-sectional analysis of hospital survivors.

Results: One hundred seventy-six patients with hypoplastic left heart syndrome and variants underwent a stage 1 reconstruction with either a right ventricle-pulmonary artery conduit $(\mathrm{n}=62)$ or a modified Blalock-Taussig shunt $(\mathrm{n}=114)$. The median duration of follow-up is 29.1 months (range, 0-57 months). By means of KaplanMeier analysis, there is no difference in survival at 3 years (right ventriclepulmonary artery conduit: $73 \%$ [95\% confidence limit, 59\%-83\%] vs modified Blalock-Taussig shunt: 69\% [95\% confidence limit, 59\%-77\%]; $P=.6$ ). One hundred twenty-four patients have undergone stage 2 reconstruction (78 modified Blalock-Taussig shunts and 46 right ventricle-pulmonary artery conduits). At the time of the stage 2 reconstruction, patients with right ventricle-pulmonary artery conduits were younger (153 days [range, 108-340 days]; modified Blalock-Taussig shunt, 176 days [range, $80-318$ days]; $P=.03$ ), had lower systemic oxygen saturation (73\% [range, 58\%-85\%] vs $77 \%$ [range, 57\%-89\%], $P<.01$ ), and had higher preoperative hemoglobin levels $(15.8 \mathrm{~g} / \mathrm{dL}$ [range, $13-21 \mathrm{~g} / \mathrm{dL}$ ] vs $14.8 \mathrm{~g} / \mathrm{dL}$ [range, $12-19 \mathrm{~g} / \mathrm{dL}$ ], $P<.01)$ compared with those of the modified Blalock-Taussig shunt group. By means of echocardiographic evaluation, there was a higher incidence of qualitative ventricular dysfunction in patients with right ventricle-pulmonary artery conduits $(14 / 46[31 \%]$ vs $9 / 73[12 \%], P=.02)$. However, no difference was observed in common atrial pressure or the arteriovenous oxygen difference.

Conclusion: Interim analyses suggest no advantage of one shunt type over another. This report raises concern of late ventricular dysfunction and outcome in patients with a right ventricle-pulmonary artery conduit.

$\mathrm{I}$ $\mathrm{n}$ the absence of transplantation, hypoplastic left heart syndrome (HLHS) and its variants require staged surgical reconstruction to palliate the anatomic abnormalities. Stage 1 reconstruction (S1R) includes aortic arch reconstruction, anastomosis of the proximal main pulmonary artery with the ascending aorta, ligation of the distal main pulmonary artery, atrial septectomy, and provision of a source of pulmonary blood flow. Recently, an alternative strategy to S1R has become popularized: replacing the modified Blalock-Taussig shunt (mBTS) with a right ventricle-pulmonary artery (RV-PA) conduit as the source of pulmonary blood flow. ${ }^{1}$ The theory behind this modification is that the use of the RV-PA conduit will 

Abbreviations and Acronyms
AVVR = atrioventricular valve regurgitation
DHCA $=$ deep hypothermic circulatory arrest
HLHS = hypoplastic left heart syndrome
mBTS = modified Blalock-Taussig shunt
$\mathrm{RV}-\mathrm{PA}=$ right ventricle-pulmonary artery
$\mathrm{S} 1 \mathrm{R}=$ stage 1 reconstruction
$\mathrm{S} 2 \mathrm{R}=$ stage 2 reconstruction
$\mathrm{S} 3 \mathrm{R}=$ stage 3 reconstruction

result in less diastolic runoff into the pulmonary vasculature and therefore improved coronary and myocardial perfusion. Several case series using the mBTS as a historical control have documented improved S1R early outcome with the use of the RV-PA conduit. ${ }^{2-6}$ However, other case series using both contemporary and historical controls have not found significant differences in early survival with the use of the RV-PA conduit. ${ }^{7-9}$ Most recently, contemporary comparison of the immediate hemodynamics after S1R with both shunt types in a randomized study did not demonstrate benefit of one shunt type versus the other. ${ }^{10}$

Using contemporary controls, we recently demonstrated no difference in surgical mortality, time to extubation, or length of hospital stay in 149 infants undergoing S1R for HLHS or variants palliated with either an mBTS or an RV-PA conduit. ${ }^{8}$ We undertook the current study to compare the midterm hemodynamics and outcomes for the 2 shunt strategies at stage 2 reconstruction (S2R). The current study objectives include defining the difference between the 2 shunt groups with regard to (1) preoperative hemodynamic parameters, as defined by cardiac catheterization and echocardiography; (2) angiographic pulmonary artery size and architecture at the S2R; (3) age and degree of illness (as defined by anticongestive medication use, use of home oxygen, and tube feedings) at the time of S2R; and (4) stage 2 morbidity and mortality.

\section{Materials and Methods}

This study is a cross-sectional case series including all patients who underwent an S1R for HLHS or variants at The Children's Hospital of Philadelphia between January 1, 2002, and May 1, 2005 ( $\mathrm{n}=176)$, with attention paid to S1R hospital survivors $(\mathrm{n}=$ 138). This is a consent-waived study approved by The Children's Hospital of Philadelphia Institutional Review Board. Sources of information included the hospital medical records, the cardiac center and cardiac intensive care databases, records and reports provided by referring cardiologists, and pertinent information obtained from the parents on telephone interview.

We reviewed the initial, pre-S2R and pre-stage 3 reconstruction (S3R) echocardiographic reports of the study patients. Qualitative measurements of systolic ventricular function, atrioventricular valve regurgitation (AVVR), and neoaortic valve regurgitation were recorded.
TABLE 1. Single-ventricle anatomy among patients with stage 1 reconstruction shunt surgical technique

\begin{tabular}{lccc}
\hline Cardiac anatomy & $\begin{array}{c}\text { BTS } \\
(\mathbf{n}=\mathbf{1 1 4})\end{array}$ & $\begin{array}{c}\text { RV-PA } \\
(\mathbf{n}=62)\end{array}$ & $\begin{array}{c}\boldsymbol{P} \\
\text { value }\end{array}$ \\
\hline $\begin{array}{l}\text { Usual hypoplastic left heart } \\
\text { syndrome }\end{array}$ & $75(66 \%)$ & $54(87 \%)$ & .004 \\
$\begin{array}{l}\text { Malaligned atrioventricular } \\
\text { canal defect }\end{array}$ & $12(10.5 \%)$ & $4(6.5 \%)$ & .53 \\
$\begin{array}{l}\text { Double-outlet right ventricle } \\
\text { with mitral or aortic stenosis }\end{array}$ & $9(8 \%)$ & $3(4.9 \%)$ & .65 \\
$\begin{array}{l}\text { Single left ventricle } \\
\text { Other* }\end{array}$ & $\begin{array}{c}6(5 \%) \\
12(10.5 \%)\end{array}$ & $\begin{array}{c}1(1.6 \%) \\
0\end{array}$ & .16 \\
\hline
\end{tabular}

Data are counts and percentages within groups. Comparison is with the $\chi^{2}$ test. $B T S$, Blalock-Taussig shunt; $R V-P A$, right ventricle-pulmonary artery conduit. *Nine cases of double-inlet left ventricle with transposition of the great arteries and aortic stenosis or interrupted aortic arch, 1 interrupted aortic arch with aortic stenosis and ventricular septal defect, 1 tricuspid stenosis with transposition of the great arteries, and 1 L-transposition of the great arteries with aortic stenosis and single left ventricle.

Oximetry, hemodynamic, and angiographic data were obtained at cardiac catheterization before S2R after achievement of conscious sedation or general anesthesia. Measured data included venous and arterial saturations, common atrial pressure, pulmonary artery pressure or pulmonary venous wedge pressure, and aortic pressure. Calculated data included arteriovenous oxygen difference and coronary perfusion pressure. Angiographic measurements were obtained from the anteroposterior or anterior oblique projections offline by a single observer to assess branch pulmonary artery anatomy and growth. The Nakata index was calculated as previously described. ${ }^{11}$ The narrowest portion of the proximal branch pulmonary artery within $1 \mathrm{~cm}$ of the shunt insertion was measured by using standard offline techniques and compared with the vessel diameter just before the take-of the lobar branches to assess pulmonary artery stenosis. The ratio of these 2 measurements was used as a measure of severity of pulmonary artery stenosis and was graded as follows: moderate-to-severe stenosis, ratio less than 0.65 ; mild stenosis, ratio 0.66 to 0.85 ; and no stenosis, ratio greater than 0.85 . The appearance of the branch pulmonary arteries was also recorded to ascertain the degree of pulmonary artery distortion qualitatively. The appearance was graded as follows: normal, diffusely narrowed, or discretely narrowed at the shunt or conduit insertion.

The operative technique for S1R has been previously described. ${ }^{8}$ There was a surgical preference for the use of the RV-PA conduit in aortic atresia and the mBTS for lesions with a single left ventricle (Table 1). S2R consisted of either a bidirectional Glenn or hemi-Fontan procedure. Patients with bilateral superior vena cavae underwent either the bilateral bidirectional Glenn procedure or the right hemi-Fontan and left bidirectional Glenn procedure. The selection of a bidirectional Glenn or hemi-Fontan procedure was at the discretion of the surgeon. Patients with heterotaxy syndrome with interrupted inferior vena cavae underwent the $\mathrm{Ka}$ washima procedure. Additional procedures, such as tricuspid valve annuloplasty or valvuloplasty, were documented. Age and size at S2R and comparative operative data, including additional cardiac 


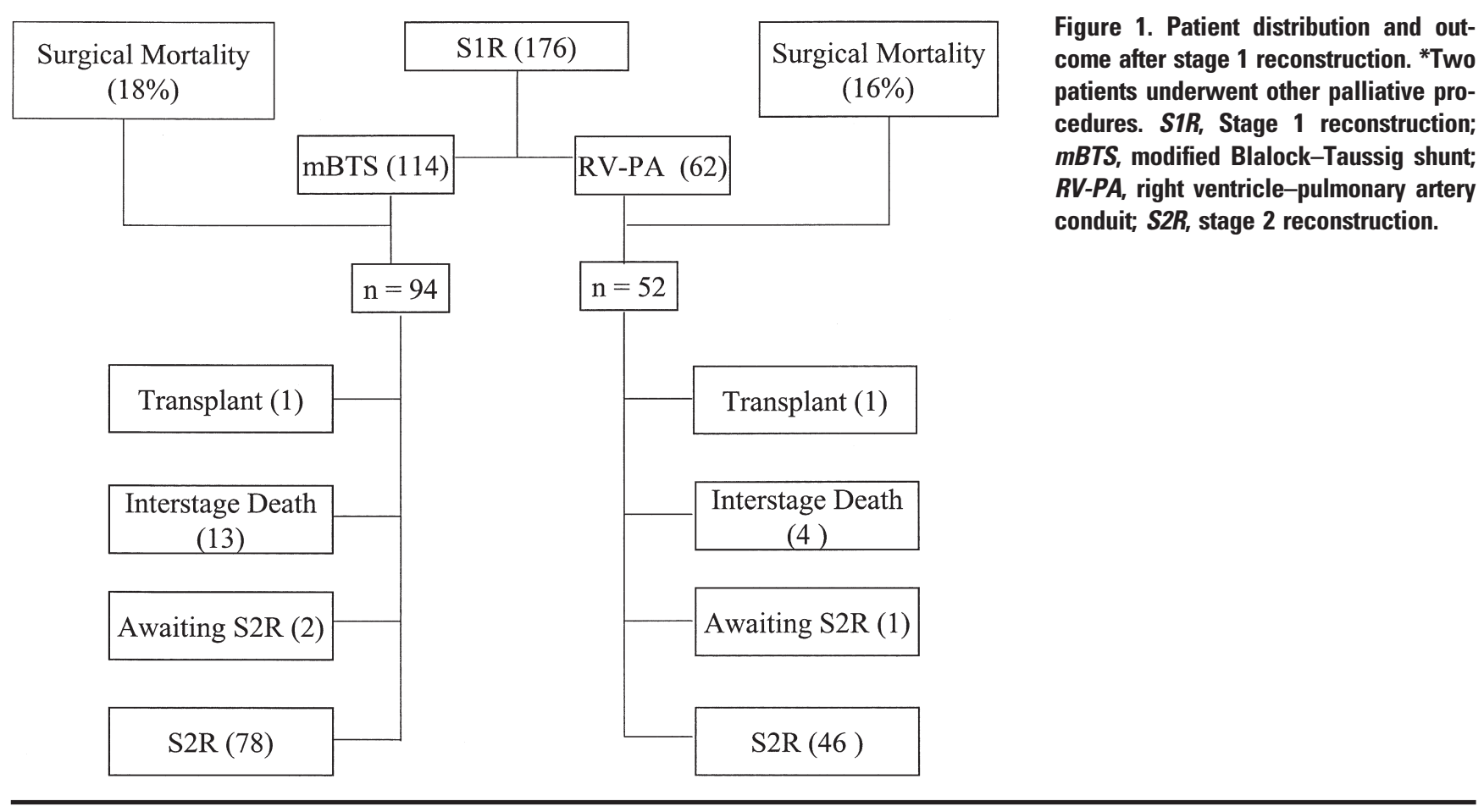

operative procedures performed, cardiopulmonary bypass time, aortic crossclamp time, and deep hypothermic circulatory arrest (DHCA) time, were recorded. Postoperative data, including total length of intubation, incidence of reintubation, and cardiac intensive care unit and hospital lengths of stay, were also recorded. Need for extracorporeal membrane oxygenation, cardiopulmonary resuscitation, reoperation, or cardiac catheterization before discharge or listing for transplantation were documented. Other perioperative morbid events, including placement of chest tubes, postoperative seizures, and wound infections, were documented. The incidence of rehospitalization was obtained to assess the postdischarge morbidity. The indications for admission, length of stay, invasive procedures performed, and outcome were ascertained from the medical records or from the parents directly. Other operative procedures, including bronchoscopy, tracheostomy, and gastrostomy tube placement, were documented as well.

Data are presented as medians (ranges) or means ( \pm standard deviation) for continuous variables and as a count and percentage for dichotomous variables. Continuous variables were compared by using the Mann-Whitney test and the Student $t$ test. The Fisher exact test and $\chi^{2}$ analyses were used for dichotomous and categoric variables. Kaplan-Meier survival curves using a composite end point of death or transplantation were stratified by shunt type. All data were analyzed by using STATA 8.0 software (STATA Corp, College Station, Tex).

\section{Results}

\section{Patient Population}

There were 176 patients who underwent S1R for HLHS or variants. An mBTS was placed in 114 patients, and an RV-PA conduit was placed in 62 patients (Figure 1). Pa- tients with aortic atresia were more likely to get an RV-PA conduit (mBTS, 30\%; RV-PA, 70\%; $P \leq .01$ ). Anatomic subtypes are described in Table 1. Surgical mortality (death at less than 30 days postoperatively or before hospital discharge) was similar between the 2 groups (mBTS, 20/ 114; RV-PA, $10 / 62 ; P=.81$ ) for S1R. Of the $146 \mathrm{~S} 1 \mathrm{R}$ survivors, 124 have undergone S2R (mBTS, 78/94; RV-PA, $46 / 52 ; P=.33$ ). Four patients have undergone other palliative procedures (mBTS, 2/94; RV-PA, 2/52; $P=.74$ ), and 1 patient is awaiting S2R (Figure 1). Other palliative procedures included transplantation and additional shunt placement. Interstage death, defined as death after hospital discharge from S1R but before S2R, accounts for the remaining 17 patients. No significant difference in the incidence of interstage death between shunt types (mBTS, 13/ 94; RV-PA, 4/52; $P=.4$ ) was found.

\section{Preoperative Morbidity}

There was no difference in medication use or in the occurrence of supplemental nasogastric or gastric tube feedings (Table 2). Significantly more infants in the RV-PA conduit group required home oxygen than did infants with an mBTS shunt (29/46 vs $5 / 81, P=.04)$ and presented with higher hemoglobin levels at the time of cardiac catheterization (15.8 g/dL [range, 13-20 g/dL] vs $14.8 \mathrm{~g} / \mathrm{dL}$ [range, 12-19 $\mathrm{g} / \mathrm{dL}], P=.01)$. At the time of S2R, infants in the RV-PA conduit group were younger (RV-PA: 153 days [range, 108-340 days] vs mBTS: 187 days [range, 80-489 days], 
TABLE 2. Medication, home oxygen, and supplemental feeding use before stage 2 reconstruction

\begin{tabular}{lccc}
\hline & $\begin{array}{c}\text { mBTS } \\
(\mathbf{n}=\mathbf{8 1})\end{array}$ & $\begin{array}{c}\text { RV-PA } \\
(\mathbf{n}=46)\end{array}$ & $\begin{array}{c}\boldsymbol{P} \\
\text { value }\end{array}$ \\
\hline Medications & & & \\
$\quad$ Digoxin & $33(41 \%)$ & $13(28 \%)$ & .15 \\
ACE-I & $35(43 \%)$ & $15(33 \%)$ & .14 \\
$\quad$ Diuretic & $59(73 \%)$ & $30(65 \%)$ & .19 \\
Anticoagulant & $74(91 \%)$ & $40(87 \%)$ & .32 \\
$\mathrm{H}_{2}$ blocker/metoclopramide & $37(46 \%)$ & $25(54 \%)$ & .36 \\
$\quad$ (Reglan) & & & \\
Spironolactone (Aldactone) & $8(10 \%)$ & $1(2 \%)$ & .15 \\
Other* & $20(25 \%)$ & $10(22 \%)$ & .83 \\
$\quad$ Use of $\geq 3$ medications & $45(56 \%)$ & $23(50 \%)$ & .68 \\
Home oxygen & $5(6 \%)$ & $9(20 \%)$ & .03 \\
Nasogastric/gastric tube feedings & $23(28 \%)$ & $11(24 \%)$ & .37 \\
\hline
\end{tabular}

$m B T S$, Modified Blalock-Taussig shunt; RV-PA, right ventricle-pulmonary artery conduit; $A C E$, angiotensin-converting enzyme. *Amiodarone, diazepam, ferrous sulfate, levothyroxine, methadone, phenobarbital, potassium chloride, and budesonide (Pulmicort).

$P=.03)$ compared with the mBTS group but did not differ in size as measured by weight at the time of surgical intervention (RV-PA: $6.1 \pm 1.1 \mathrm{~kg}$ vs mBTS: $6.2 \pm 1.2 \mathrm{~kg}$, $P=.62)$ or by body surface area (RV-PA: $0.31 \pm 0.04 \mathrm{~m}^{2}$ vs mBTS: $\left.0.31 \pm 0.04 \mathrm{~m}^{2}, P=.9\right)$. Both surgical and transcatheter shunt interventions were more common in the RV-PA conduit group (surgical: mBTS, 12/114; RV-PA, 13/62; $P=.06$; transcatheter: mBTS, 6/114; RV-PA, 9/62; $P=.04)$ compared with the mBTS group. There was no difference in surgical (mBTS, 4/114; RV-PA, 0/62; $P=$ .13) or transcatheter (mBTS, 20/114; RV-PA, 10/62; $P=$ .81) relief of arch obstruction between groups.

\section{Preoperative Echocardiographic Data}

Preoperative ventricular systolic function was significantly different between shunt types. Qualitative moderate-tosevere systolic ventricular dysfunction was present in $31 \%$ of patients in the RV-PA group in comparison with $12 \%$ in the mBTS group $(P=.03)$. A similar incidence of moderateto-severe tricuspid regurgitation was found between the 2 groups. Significant neoaortic regurgitation was uncommon.

\section{Preoperative Cardiac Catheterization Data}

There were consistent and significant differences in aortic saturation, diastolic arterial pressure, and coronary perfusion pressure between shunt types at the pre-S2R catheterization (Table 3). There was no significant difference between the 2 groups with respect to mixed systemic venous saturation obtained in the superior vena cava, arteriovenous oxygen difference, common atrial pressure, or pulmonary artery pressure (Table 3). The calculated Qp/Qs ratio was significantly higher in those patients with an $\mathrm{mBTS}$ (mBTS, $1.7 \pm 0.86$; RV-PA, $1.3 \pm 0.69 ; P=.025)$.
TABLE 3. Pre-stage 2 reconstruction catheterization data

\begin{tabular}{|c|c|c|c|}
\hline & $\begin{array}{c}\text { mBTS } \\
(n=78)\end{array}$ & $\begin{array}{c}\text { RV-PA } \\
(n=46)\end{array}$ & $\begin{array}{c}P \\
\text { value }\end{array}$ \\
\hline Aortic saturation (\%) & 77 (57-89) & $73(58-85)$ & $<.01$ \\
\hline $\begin{array}{l}\text { Superior vena cava } \\
\text { saturation }(\%)\end{array}$ & $50(30-66)$ & $47(26-63)$ & .15 \\
\hline $\mathrm{AVO}_{2}$ difference & $28(7-50)$ & $28(15-50)$ & .54 \\
\hline Aortic systolic BP (mm Hg) & $91(68-135)$ & $92(56-132)$ & .77 \\
\hline Aortic diastolic BP (mm Hg) & $40(20-57)$ & $48(29-60)$ & $<.01$ \\
\hline $\begin{array}{l}\text { Coronary perfusion } \\
\text { pressure }(\mathrm{mm} \mathrm{Hg})\end{array}$ & $31(12-47)$ & $39(21-53)$ & $<.01$ \\
\hline $\begin{array}{l}\text { Common atrial pressure } \\
(\mathrm{mm} \mathrm{Hg})\end{array}$ & $8(3-15)$ & $8(4-14)$ & .79 \\
\hline PAP or PVWP (mm Hg) & $15(8-22)$ & $14(10-25)$ & .30 \\
\hline Qp/Qs & $1.6(0.47-4.6)$ & $1.3(0.19-3.6)$ & .03 \\
\hline LPA diameter (mm) & $5.8(2.7-11.8)$ & $7(4.2-11.8)$ & .01 \\
\hline RPA diameter (mm) & $6.2(2.7-12.3)$ & $6.1(1.9-9.7)$ & .39 \\
\hline
\end{tabular}

Data are reported as medians (ranges). $m B T S$, Modified Blalock-Taussig shunt; $R V-P A$, right ventricle-pulmonary artery conduit; $A V_{2}$, arteriovenous oxygen; $B P$, blood pressure; $P A P$, pulmonary artery pressure; $P V W P$, pulmonary venous wedge pressure; $L P A$, left pulmonary artery; $R P A$, right pulmonary artery.

By means of angiography, there were differences in pulmonary artery size, degree of stenosis, and degree of distortion both within the RV-PA group and between shunt types. The left pulmonary artery was significantly larger than the right pulmonary artery within the RV-PA group (left pulmonary artery, $7.04 \pm 1.8 \mathrm{~mm}$; right pulmonary artery, $5.99 \pm 2 \mathrm{~mm} ; P=.01$ ), as well as being significantly larger than the left pulmonary artery in the mBTS group (mBTS, $6.17 \pm 1.8 \mathrm{~mm}$; RV-PA, $7.04 \pm 1.8 \mathrm{~mm} ; P=.01$ ). Between shunt types, there was moderate or severe right pulmonary artery stenosis (mBTS, 23\%; RV-PA, 46\%; $P=$ $.004)$ more frequently, as well as more frequent long-segment pulmonary artery hypoplasia or distortion at the shunt insertion site in the RV-PA conduit group (mBTS, 36\%; RV-PA, $58 \% ; P=.005)$ compared with the mBTS group.

There were 5 deaths ( 1 surgical and 4 nonsurgical) in the RV-PA conduit group and 4 deaths ( 3 surgical and 1 nonsurgical) in the mBTS group after S2R $(P=.47)$. A total of 4 patients were listed for heart transplantation after S2R, 3 in the RV-PA group and 1 in the mBTS group. Of the 3 from the RV-PA group, 2 underwent transplantation and 1 died of sepsis while listed for transplantation.

\section{S2R Morbidity}

S2R consisted of the bidirectional Glenn or hemi-Fontan procedure for all, with the exception of 3 patients who underwent the Kawashima procedure and 12 patients who underwent bilateral bidirectional Glenn or right sided hemiFontan and left bidirectional Glenn procedures because of bilateral superior vena cavae. Ten patients underwent tricuspid valvuloplasty at the time of S2R (mBTS, 4/73; 
TABLE 4. Morbidity and mortality data by shunt type after stage 2 reconstruction

\begin{tabular}{lccc}
\hline & $\begin{array}{c}\text { mBTS } \\
(\mathbf{n}=\mathbf{7 3})\end{array}$ & $\begin{array}{c}\text { RV-PA } \\
(\mathbf{n}=\mathbf{4 6})\end{array}$ & $\begin{array}{c}\boldsymbol{P} \\
\text { value }\end{array}$ \\
\hline Time to extubation (d) & $0(0-79)$ & $0(0-8)$ & .80 \\
No. of failed first extubations & 7 & 2 & .62 \\
Cardiac ICU length of stay (d) & $3(1-100)$ & $4(0-40)$ & .71 \\
Hospital length of stay (d) & $5(2-100)$ & $6(2-60)$ & .09 \\
Sternal wound infection & 6 & 3 & .92 \\
Postoperative seizures & 5 & 4 & .64 \\
Listed for heart transplantation & 1 & 3 & .30 \\
Death (surgical and late) & 4 & 5 & .47 \\
\hline
\end{tabular}

$m B T S$, Modified Blalock-Taussig shunt; RV-PA, right ventricle-pulmonary artery conduit; ICU, intensive care unit.

RV-PA, 6/46; $P=.27$ ). Cardiopulmonary bypass, crossclamp, and DHCA times for S2R were not statistically different between shunt types. DHCA was used in $63 \%$ of the patients (mBTS, 41/73; RV-PA, 34/46; $P=.08$ ).

There was no difference in the time to initial extubation, with the majority of the patients in both groups extubated on the day of surgical intervention. Seven patients in the mBTS group failed the first attempted extubation in comparison with 2 patients in the RV-PA group. There was no difference in the intensive care unit or hospital length of stay after S2R between groups (Table 4). Pleural effusion requiring chest tube placement occurred in 4 patients in the RV-PA group and 12 patients in the mBTS group during the surgical hospitalization. A total of 9 patients underwent cardiac catheterization before discharge. Of those with prior RV-PA conduits, 2 of the 5 patients underwent hemodynamic studies only, and 4 underwent pulmonary artery angioplasty or placement of a stent within 1 or both pulmonary arteries. Aortopulmonary collateral arteries were coil occluded in 2 patients and a venous decompressing vein was coil occluded in 1 patient in the mBTS group. Other morbidities included the use of extracorporeal membrane oxygenation with subsequent decannulation and listing for heart transplantation in 1 patient in the mBTS group, 9 patients with seizures postoperatively, 9 patients with superficial or deep wound infection (Table 4), and 1 patient in the mBTS group with alanine and aspartate aminotransferase levels of greater than $1000 \mathrm{mg} / \mathrm{dL}$.

\section{Follow-up}

Twenty-two patients with mBTS and 11 patients with RV-PA conduits had a total of 58 documented readmissions after discharge from S2R. Of the 21 readmissions in the RV-PA conduit group, 11 were for cardiac indications. Six patients were rehospitalized for poor ventricular function, of whom 2 underwent transplantation and 5 had pleural effusions that required drainage. Other indications for readmission included tracheitis in 2 patients with tracheostomies,

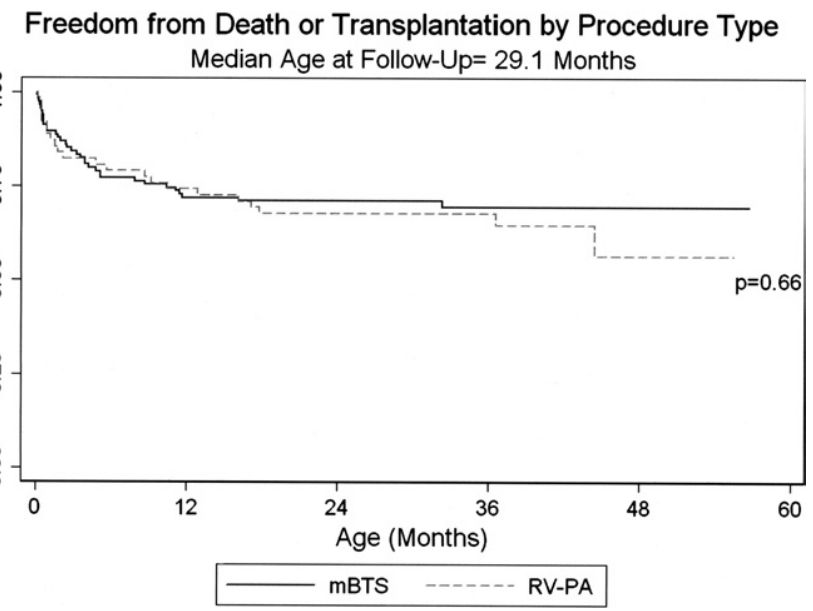

Figure 2. Kaplan-Meier freedom from death or transplantation after stage 1 reconstruction by shunt type. $m B T S$, Modified Blalock-Taussig shunt; $R V$-PA, right ventricle-pulmonary artery conduit.

other infection in 5 patients, and dehydration in 1 patient. The median length of stay was 6 days (range, 1-132 days). Twenty of the 37 readmissions in the mBTS group were for cardiac indications. Nine readmissions were for poor ventricular function, 7 for pleural effusions that required drainage, and there were readmissions for 2 patients with mediastinitis who required surgical debridement. One patient accounted for 10 readmissions in this group; however, 8 admissions were related to therapy for concurrent neuroblastoma. The median length of stay for readmissions in this group was 4 days (range, 1-70 days).

The median length of follow-up is 29.1 months and is not different between groups. Overall survival and freedom from death or transplantation by means of Kaplan-Meier analysis are no different between groups (Figure 2). To date, 58 patients have subsequently undergone S3R (mBTS, 40/ 78; RV-PA, 18/46). There have been 2 deaths after S3R, both in the mBTS group. As determined by means of echocardiography at the time of S3R, ventricular function was moderately or severely decreased in $11 \%$ of patients who initially underwent S1R with an RV-PA conduit in comparison with $2.5 \%$ of patients who had an $\mathrm{mBTS}$ at S1R (mBTS, 1/40; RV-PA, 2/18; $P=.3$ ). Significant AVVR and neoaortic regurgitation tended to be more common in patients in the RV-PA conduit group compared with in the mBTS group (AVVR: mBTS, 8/40; RV-PA, 8/18; $P=.1$; neoaortic regurgitation: $\mathrm{mBTS}, 3 / 40 ; \mathrm{RV}-\mathrm{PA}, 5 / 18 ; P=.1$ ). Of all patients currently alive, $34 \%$ receive ancillary services, such as occupational, physical, or speech therapy, and $33 \%$ have gross motor delays, speech delays, or both, as reported by parents. Thirty-five percent of this same cohort routinely requires evaluation by other subspecialists, includ- 
ing neurology, otolaryngology, gastroenterology, and general surgery. The use of ancillary services is similar between shunt types.

\section{Discussion}

Multiple factors have resulted in improved survival among infants born with functional single-ventricle lesions. These factors include surgical modifications, improved surgical technique, modifications to preoperative and postoperative care, and a better understanding of the cardiac physiology of a single-ventricle patient undergoing surgical reconstruction. ${ }^{12-17}$ The most recent modification is the use of an RV-PA conduit. This technique was first described by Norwood and colleagues ${ }^{18}$ in the early 1980s but was abandoned in favor of a systemic to pulmonary shunt. Multiple centers have reported improved surgical survival with the use of this conduit when compared with historical controls. ${ }^{1,5}$

Hemodynamic evaluation outside of the immediate postoperative period of infants undergoing S1R with an RV-PA conduit has been limited. Maher and associates ${ }^{19}$ recently described the comparative hemodynamic profiles of 24 infants before S2R. This study demonstrated higher aortic diastolic pressure, higher coronary perfusion pressure, and larger pulmonary arteries in those patients who underwent reconstruction with an RV-PA conduit. ${ }^{19}$ Januszewska and coworkers ${ }^{20}$ demonstrated increased pulmonary artery size in patients with an RV-PA conduit when evaluated echocardiographically or intraoperatively at the time of S2R for a consecutive series of 78 patients who had undergone S1R with either an mBTS or RV-PA conduit for HLHS.

Midterm and long-term ventricular performance is also a concern in those patients who undergo S1R with an RV-PA conduit because of the need for a ventricular incision at the time of conduit placement. Tanoue and associates ${ }^{21}$ describe comparable ventricular performance, as assessed by means of echocardiography, at the time of S2R between shunt types; however, after the S2R and total cavopulmonary connection (S3R), ventricular contractility was found to be inferior in those with an RV-PA conduit. Others describe improved early ventricular function in patients with RV-PA conduit, as assessed by means of strain Doppler echocardiography. ${ }^{22}$

In the current study infants with an RV-PA conduit were younger and more hypoxemic at the time of S2R. They were the same weight with less pulmonary blood flow, resulting in a more balanced systemic and pulmonary blood flow with a comparative degree of medically treated heart failure as those infants with an mBTS. The differences between shunt types did not appear to affect S2R hospitalization or interstage death. The more balanced Qp/Qs ratio and increased hypoxemia is consistent with that of others routinely using a 5-mm RV-PA conduit. ${ }^{2-4,6}$ In our cohort less pulmonary blood flow might be a result of more distortion of the pulmonary arteries, as well as a smaller right pulmonary artery within this group as a whole.

Little is known about changes in pulmonary architecture with the use of the RV-PA conduit. Asymmetric pulmonary artery growth with left pulmonary artery narrowing has been previously described. ${ }^{23}$ In the current study the pulmonary arteries at the time of S2R catheterization appeared "tented," or pulled forward, as the RV-PA conduit inserted to the left of the neoaorta into the confluence of the branch pulmonary arteries. This tenting resulted in a significant amount of narrowing of the branch pulmonary arteries at the insertion point. This is supported by a recent report comparing the shunt types of patients undergoing S1R with use of both shunt types. ${ }^{24}$ Stenoses were found to be more severe, causing significant reduction in the pulmonary artery dimension in those patients who had an RV-PA conduit. ${ }^{24}$ In the current comparative study the positioning of the shunt also appears to have influenced pulmonary artery size, resulting in preferential blood flow to the left pulmonary artery.

There are limited data available on the effect of an incision in the single right ventricle for the placement of an RV-PA conduit on systemic ventricular function. We found, by means of echocardiographic assessment, that patients with an RV-PA conduit at S1R had more ventricular dysfunction at the time of S2R. These infants had ventricular dysfunction during the interstage time interval because they had normal ventricular function at the time of initial presentation and the time of hospital discharge after S1R. Tanoue and associates ${ }^{21}$ evaluated the ventricular performance (as assessed by means of evaluation of contractility), afterload, and ventricular efficiency in a group of patients with HLHS who had undergone complete staged repair. Midterm or pre-S2R assessment was that there was no difference in ventricular efficiency; however, after S2R and S3R, contractility in patients who had previously undergone palliation at the time of S1R with an RV-PA conduit was inferior to that of patients who underwent S1R with a mBTS. ${ }^{21}$ The role of afterload reduction was underscored in this study because contractility might have decreased, but ventricular efficiency remained unchanged because the afterload of the ventricle had also been reduced. Nearly $80 \%$ of patients treated with an RV-PA conduit at S1R are currently on afterload reduction compared with $50 \%$ of patients with an mBTS.

Survival was similar between shunt types at a median of 29 months' follow-up. It is plausible to postulate that although there is improved coronary perfusion between S1R and S2R that might be protective in regard to interstage death, its effect on long-term protection of ventricular function might not be enough to overcome the effects of the ventricular incision. 
This study is limited by a nonrandomized patient population, with possible uneven distribution of unrecognized preoperative risk factors between shunt groups. It is a recent study group, and important late outcomes, such as arrhythmia, sudden death, and ventricular dysfunction, might not have yet occurred. Finally, this study might not be powered to evaluate small differences between comparison groups.

The ideal patient awaiting S2R is an infant of reasonable weight with balanced systemic and pulmonary circulation, good ventricular function with minimal AVVR, minimal semilunar valve regurgitation, and good-sized pulmonary arteries. What this study has demonstrated is that there are differences in the ventricular performance by means of echocardiography, coronary perfusion pressure, degree of hypoxemia, amount of pulmonary blood flow by means of hemodynamic evaluation, and pulmonary artery growth between groups of infants who have undergone S1R with either an RV-PA conduit or mBTS. This study did not show that these differences translate into improved outcome for a select shunt strategy. This might be due to no actual difference in outcome between shunt types, the limitation of a nonrandomized patient population, or insufficient numbers of patients to demonstrate a meaningful difference between shunt strategies. The limited, current follow-up data would suggest that infants with an RV-PA conduit at the time of S1R who present with ventricular dysfunction at the time of S2R do not appear to recover function with unloading of the ventricle with $\mathrm{S} 2 \mathrm{R}$. It is unclear whether the long-term outcome of infants undergoing reconstruction with this type of pulmonary blood flow will be better than that currently experienced by infants who underwent S1R with an mBTS. This underscores the need for continued follow-up and critical analysis of data acquired in the ongoing randomized clinical trial of these 2 surgical strategies for the treatment of HLHS.

\section{References}

1. Sano S, Ishino K, Kawada M, Arai S, Kasahara S, Asai T, et al. Right ventricle-pulmonary artery shunt in first-stage palliation of hypoplastic left heart syndrome. J Thorac Cardiovasc Surg. 2003;126:504-10.

2. Pizarro C, Malec E, Maher KO, Januszewska K, Gidding SS, Murdison KA, et al. Right ventricle to pulmonary artery conduit improves outcome after stage I Norwood for hypoplastic left heart syndrome. Circulation. 2003;108(suppl II):II155-60.

3. Pizarro C, Norwood WI. Right ventricle to pulmonary artery conduit has a favorable impact on postoperative physiology after stage I Norwood: preliminary results. Eur J Cardiothorac Surg. 2003;23: 991-5.

4. Malec E, Januszewska K, Kolcz J, Mroczek T. Right ventricle to pulmonary artery shunt versus modified Blalock Taussig shunt in the Norwood procedure for hypoplastic left heart syndrome influence on early and late haemodynamic status. Eur J Cardiothorac Surg. 2003; 23:728-34.

5. Sano S, Ishino K, Kado H, Shiokawa Y, Sakamoto K, Yokota M, et al. Outcome of right ventricle to pulmonary artery shunt in first stage palliation of hypoplastic left heart syndrome: a multi-institutional study. Ann Thorac Surg. 2004;78:1951-8.
6. Mair R, Tulzer G, Sames E, Lechner E, Steiner J, Hofer A, et al. Right ventricular to pulmonary artery conduit instead of modified Blalock Taussig shunt improves postoperative hemodynamics in newborns after the Norwood operation. J Thorac Cardiovasc Surg. 2003;126: 1378-84.

7. Mahle WT, Cuadrado AR, Tam VK. Early experience with a modified Norwood procedure using right ventricle to pulmonary artery conduit. Ann Thorac Surg. 2003;76:1084-9.

8. Tabbutt S, Dominguez TE, Ravishankar C, Marino BS, Gruber PJ, Wernovsky G, et al. Outcomes after the stage I reconstruction comparing the right ventricular to pulmonary artery conduit with the modified Blalock Taussig shunt. Ann Thorac Surg. 2005;80:1582-91.

9. Bradley SM, Simsic JM, Mcquinn TC, Haviv DM, Shirali GS, Atz AM. Hemodynamic status after the Norwood procedure: a comparison of right ventricle to pulmonary artery connection versus modified Blalock Taussig shunt. Ann Thorac Surg. 2004;78:933-41.

10. Ghanayem NS, Jaquiss RDB, Cava JR, Frommelt PC, Mussatto KA, Hoffman GM, et al. Right ventricle-to-pulmonary artery conduit versus Blalock-Taussig shunt: a hemodynamic comparison. Ann Thorac Surg. 2006;82:1603-10.

11. Nakata S, Imai Y, Takanashi Y, Kurosawa H, Tezuka K, Nakazawa M, et al. A new method for the quantitative standardization of crosssectional areas of the pulmonary arteries in congenital heart diseases with decreased pulmonary blood flow. J Thorac Cardiovasc Surg. 1984;88:610-9.

12. Bove EL, Lloyd TR. Staged reconstruction for hypoplastic left heart syndrome. Contemporary results. Ann Surg. 1996;224:387-95.

13. Bove EL. Current status of staged reconstruction for hypoplastic left heart syndrome. Pediatr Cardiol. 1998;19:308-15.

14. Mahle WT, Spray TL, Wernovsky G, Gaynor JW, Clark BJ. Survival after reconstructive surgery for hypoplastic left heart syndrome: a 15 year experience from a single institution. Circulation. 2000;102(suppl 3): III36-41.

15. Malec E, Januszewska K, Kolz J, Pajak J. Factors influencing early outcome of Norwood procedure for hypoplastic left heart syndrome. Eur J Cardiothorac Surg. 2000;18:202-6.

16. Azakie A, Merklinger Sl, McCrindle BW, Van Arsdell GS, Lee KJ, Benson LN, et al. Evolving strategies and improving outcomes of the modified Norwood procedure: a 10 year single institution experience. Ann Thorac Surg. 2001;72:1349-53.

17. Tweddell JS, Hoffman GM, Mussatto KA, Fedderly RT, Berger S, Jaquiss RD, et al. Improved survival of patients undergoing palliation of hypoplastic left heart syndrome: lessons learned from 115 consecutive patients. Circulation. 2002;106(suppl I):I82-9.

18. Norwood WI, Lang P, Castaneda AR, Campbell DN. Experience with operations for hypoplastic left heart syndrome. J Thorac Cardiovasc Surg. 1981;82:511-9.

19. Maher KO, Pizarro C, Gidding SS, Januszewska K, Malec E, Norwood WI, et al. Hemodynamic profile after the Norwood procedure with right ventricle to pulmonary artery conduit. Circulation. 2003;108:782-4.

20. Januszewska K, Kolcz J, Mroczek T, Procelewska M, Malec E. Right ventricle to pulmonary artery shunt and modified Blalock Taussig shunt in preparation to hemi-Fontan procedure in children with hypoplastic left heart syndrome. Eur J Cardiothorac Surg. 2005;27: 956-61.

21. Tanoue Y, Kado H, Shiokawa Y, Fusazaki N, Ishikawa S. Midterm ventricular performance after Norwood procedure with right ventricularpulmonary artery conduit. Ann Thorac Surg. 2004;78:1965-71.

22. Hughes ML, Shekerdemian LS, Brizard CP, Penny DJ. Improved early ventricular performance with a right ventricle to pulmonary artery conduit in stage 1 palliation for hypoplastic left heart syndrome: evidence from strain Doppler echocardiography. Heart. 2004;90: 191-4.

23. Weber HS, Myers JL. Association of asymmetric pulmonary artery growth following palliative surgery for hypoplastic left heart syndrome with ductal coarctation, neoaortic arch compression and shunt-induced pulmonary artery stenosis. Am J Cardiol. 2003;91:1503-6.

24. Rumball EW, McGuirk SP, Stumper O, Laker SJ, de Giovanni JV, Wright JG, et al. The RV-PA conduit stimulates better growth of the pulmonary arteries in hypoplastic left heart syndrome. Eur J Cardiothorac Surg. 2005;27:801-6. 